\title{
高速遠心成形アルミナの焼結挙動と機械的性質におよぼす粉末特性の影響
}

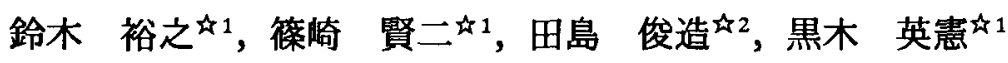 \\ *1 広島大学工学部, $=739-8527$ 東広島市鏡山 1-4-1. \\ 《2 広島大学教育学部, $=739-8524$ 東広島市鏡山 1-1-1.
}

\section{Effect of Powder Characteristics on Sintering Behavior and Mechanical Properties of Alumina Compacted by High-Speed Centrifugal Compaction Process}

\author{
Hiroyuki Y. Suzuki ${ }^{\text {} 1}$, Kenji Shinozaki ${ }^{\star 1}$, Syunzo Tashima ${ }^{\text {tै } 2}$ and Hidenori Kuroki ${ }^{\star 1}$ \\ ${ }^{4}$ Faculty of Engineering, Hiroshima University, 1-4-1 Kagamiyama, Higashi-Hiroshima 739-8527. \\ ${ }^{2}$ Faculty of Education, Hiroshima University, 1-1-1 Kagamiyama, Higashi-Hiroshima 739-8524.
}

Received February 3, 2000

\begin{abstract}
SYNOPSIS
Two types of fine $(0.2 \mu \mathrm{m})$ and pure $(99.99 \%)$ alumina powders are dispersed in ion-exchanged water and compacted into a columnar shape of $\phi 8 \times 60 \mathrm{~mm}$ by the High-Speed Centrifugal Compaction Process (HCP) at 11,500 rpm for $3 \mathrm{ks}$. Specimens are sintered at $1423-1823 \mathrm{~K}$ for $5.4 \mathrm{ks}$.

HCP alumina shows good compactability regardless of starting powder. Its behavior is slightly affected by the dispersing condition of the slip. The sintering behavior of compacts can be evaluated by grain-size/relative-density trajectory. The optimum mechanical properties are realized at a characteristic part of the curve, where the curve starts to go upward.

Bending strength of the alumina with different starting materials obeys basically one equation. So does the Vickers hardness. Therefore, the strength-microstructure diagram has validity for HCP alumina of various powders. The powder which gives lower position for grain-size/relative-density trajectory of sintered alumina gives higher mechanical properties.
\end{abstract}

\section{KEYWORDS}

alumina, slip, centrifuge, grain-size, mechanical properties

\section{1 緒言}

泥獎に $10,000 \mathrm{~g}$ 程度の遠心力を作用させる高速遠心成形法 (High-Speed Centrifugal Compaction Process, 以下 HCP) をサブ ミクロンの高純度アルミナ粉に適用すると, 得られる成形体 (HCP アルミナ)は焼結性が優れ，その焼結体の機械的特性も 他の成形法によるものより優れている ${ }^{1-4}$.この HCPアルミナ の焼結に伴う組織変化を特に緛密化と粒成長の観点から調查 すると ${ }^{2,3)}$ ，焼結温度と時間の異なる試料の粒径と密度の組み 合わせが一つの曲線になっている.また HCPアルミナ焼結体 の硬さと曲げ強さの組織 (密度・粒径) 依存性を調べ, 結果を その粒径/密度曲線に重ねて示す材質一組織ダイヤグラムを作 成することにより4,最高強度を示す焼結組織を図的に導く方 法が得られている。

しかし，既報で著者らが用いたHCPアルミナは全て同一の 粉末を出発原料にしており，特性の異なるアルミナ粉末によ る HCPアルミナの焼結挙動, 機械的性質およびその組織依存
性が，既報における実験結果と共に統一的に評価可能かどう かは，現在までに確認されていない，一般的には，アルミナ を含めたセラミックスの製造において，出発原料の特性が製 品特性に非常に大きな影翌を及ほし，特に原料粉末中に含ま れる不純物の種類と量が，その正確な検知が困難であるにも 関わらず，粒子の形状や寸法と共に製品特性に大きな影響を 与えていると考えられる。

そこで本研究では，カタログ值で平均粒径，純度が同一で 製法のみが異なる 2 種類のアルミナ粉末を使用し，両者の HCP成形および焼結挙動，さらに機械的性質を比較し，粒径/ 密度曲線による焼結性評価，ならびに材質一組織ダイヤグラ ムによる製品特性の評価の妥当性について検討する。

\section{2 実験方法}

2.1 原材料および泥漿の調製

今回新しく使用する粉末 $(\mathrm{A}$ 粉末とする)は, 既報において 
Table 1 Properties of alumina powders (analytical values supplied by the providers).

\begin{tabular}{ccccccccccc}
\hline Type & $\begin{array}{c}\text { Purity } \\
{[\%]}\end{array}$ & $\begin{array}{c}\text { Surface } \\
\text { area }\end{array}$ & $\begin{array}{c}\text { Grain } \\
\text { size }\end{array}$ & \multicolumn{4}{c}{ Impurity $[\mathrm{ppm}]$} \\
\cline { 6 - 12 } & & {$\left[\mathrm{m}^{2} / \mathrm{g}\right]$} & {$[\mu \mathrm{m}]$} & $\mathrm{Si}$ & $\mathrm{Fe}$ & $\mathrm{Na}$ & $\mathrm{K}$ & $\mathrm{Ca}$ & $\mathrm{Mg}$ & $\mathrm{Cu}$ \\
\hline $\mathrm{A}$ & 99.99 & 10.4 & 0.2 & 12 & 6 & 2 & - & - & 3 & $1>$ \\
$\mathrm{B}$ & 99.99 & 15.1 & 0.2 & 1 & 9 & 3 & 2 & 2 & 1 & - \\
\hline
\end{tabular}

使用している粉末 (B 粉末とする) と同一の純度 ( 公称純度 $99.99 \%$ ) と粒径(平均粒径 $0.2 \mu \mathrm{m}$ ) を持ち, 粒径分布の狭いアル ミナである. 両粉末の特性を Table 1 に示す.

泥漿調製は既報 ${ }^{1-4}$ ) に準じ，25mass\%の超純水 (比抵抗值 $18 \mathrm{M} \Omega \mathrm{cm})$ 中に $75 \mathrm{mass} \%$ のアルミナ粉末を分散させる. 泥漿中 には分散剤として 0.6 mass\%のポリカルボン酸アンモニウム, 結合材として0.1mass\%のアクリルポリマーをそれぞれ添加す る.これは, $\mathrm{B}$ 粉末の成形のための最適条件である. 泥漿は 所定時間 (172.8ks) 調製後, E 型粘度計によってずり速度 1.9$390 \mathrm{~s}^{-1}$ の間での見かけ粘度を測定している.

\section{2 成形および成形体の評価}

成形方法も既報に準じる. 内径 $8 \mathrm{~mm}$ でアルミニウム合金製 の円筒金型中に泥漿を約 $90 \mathrm{~mm}$ の高さ $\left(\right.$ 体積 $\left.4.5 \mathrm{~cm}^{3}\right)$ まで入れ, ロー夕半径が金型底部で $120 \mathrm{~mm}$ の高速遠心機を用い, ロー夕 回転数 $11,500 \mathrm{rpm}$ で $3 \mathrm{ks}$ 間成形を行っている.

成形体粒子充填率は, 成形体を乾燥して 773K-3.6ks の条件 で脱脂後 $1073 \mathrm{~K}-3.6 \mathrm{ks}$ で仮焼結した試料を使用し, アルキメ デス法によって測定している.

\section{3 焼結および焼結体の評価}

成形体は乾燥後, 温度 $1423-1823 \mathrm{~K}$ の範囲で $5.4 \mathrm{ks}$ 間, 大気 中で焼結する，密度はアルキメデス法で測定し，焼結組織の 評価は, 常温で破壊した破面を SEM 観察することにより行

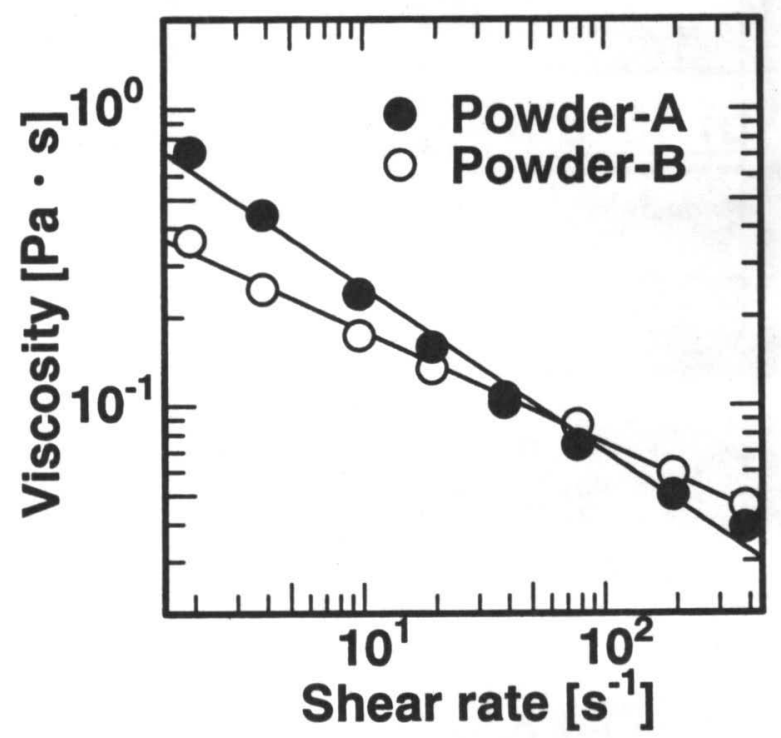

Fig.1 Viscosities of slips as a function of share rate (logarithmic scale).
い, また粒子径は, 断面の熱腐食面から線分法により求めた

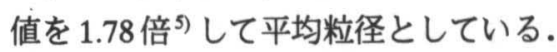

焼結体の機械的特性としては, ビッカース硬さ Hvおよび 4 点曲げ強さ $\sigma$ をそれぞれ JIS R 1610 (硬さ), JIS R 1601 (曲 げ強さ)に従って測定している.

\section{3 実験結果}

3.1 泥墏の特性

A, B両粉末をそれぞれ所定時間ボールミルで分散処理し泥 漿とした後に, ずり速度を変化させたときの見かけ粘度の変 化をFig.1に示す. 両者とも両対数図上で傾きを持った直線で 表され, 典型的な準粘性流動のである. また, A 粉の泥漿の方 が $\mathrm{B}$ 粉の泥漿よりも直線の傾きが大きく, ずり速度に対する

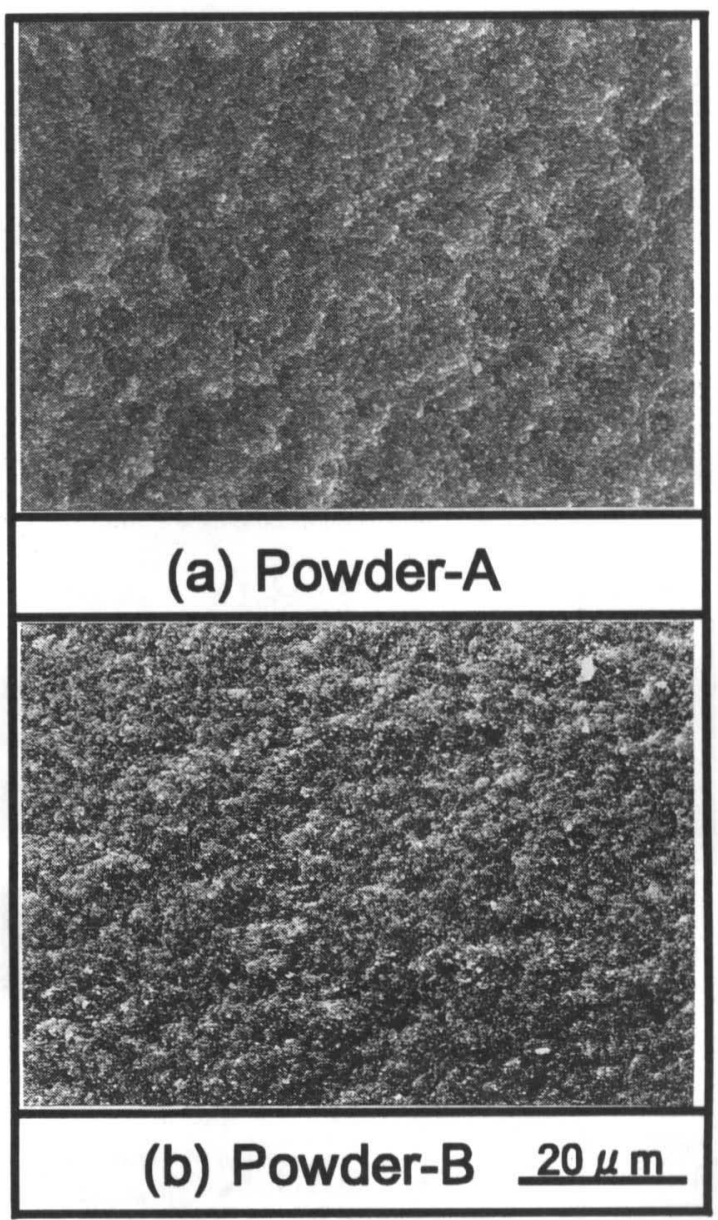

Fig.2 Fracture surfaces of green compacts. 
見かけ粘度の変化が大きい。

\section{2 成形体の特性}

A, B 両粉末による成形体破面の SEM 写真を Fig.2 に, 粒子 充填率を Table 2 に示す. A 粉の成形体の方が破面の凹凸はや や大きく,また粒子充填率も A 粉の成形体の方が約 $1.5 \%$ 程度 低いが, 両者とも明らかな欠陥等は認められず均質に粒子が 充填されている.

3.3 焼結条件と焼結体の組織の関係

\subsection{1 相対密度}

A粉成形体について焼結温度による相対密度の変化を Fig.3 に示す.この図には，比較のために既報 ${ }^{2)} て ゙$ 報告した B 粉焼 結体の結果も合わせて載せている．また，焼結体破面の SEM 写真を Fig.4に示す.

Fig.3によると, 焼結温度 1423KではA 粉焼結体はB 粉焼結 体に比べて相対密度が約 $8 \%$ 低い.両者とも焼結温度の上昇に

Table 2 Comparison of green densities.

\begin{tabular}{cc}
\hline Type & Packing density [\%] \\
\hline A & 63.6 \\
B & 62.2 \\
\hline
\end{tabular}

伴って密度も上昇するが, B 粉焼結体が焼結温度 $1503 \mathrm{~K}$ で相 対密度約 99\% に達するのに対して，A 粉焼結体は焼結密度 1573Kで相対密度約 $98 \%$ となり, その後も密度は緩やかに上 昇を続けて 1773Kで 99\%に達している．また，A粉焼結体の

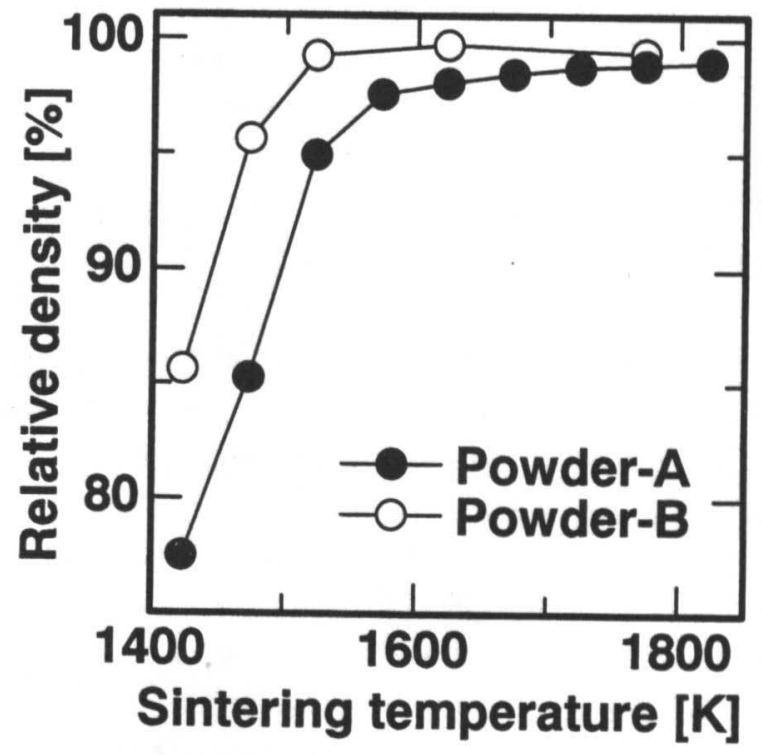

Fig.3 Relative densities of sintered compacts as a function of sintering temperature; sintered at $1423-1823 \mathrm{~K}$ for $5.4 \mathrm{ks}$.

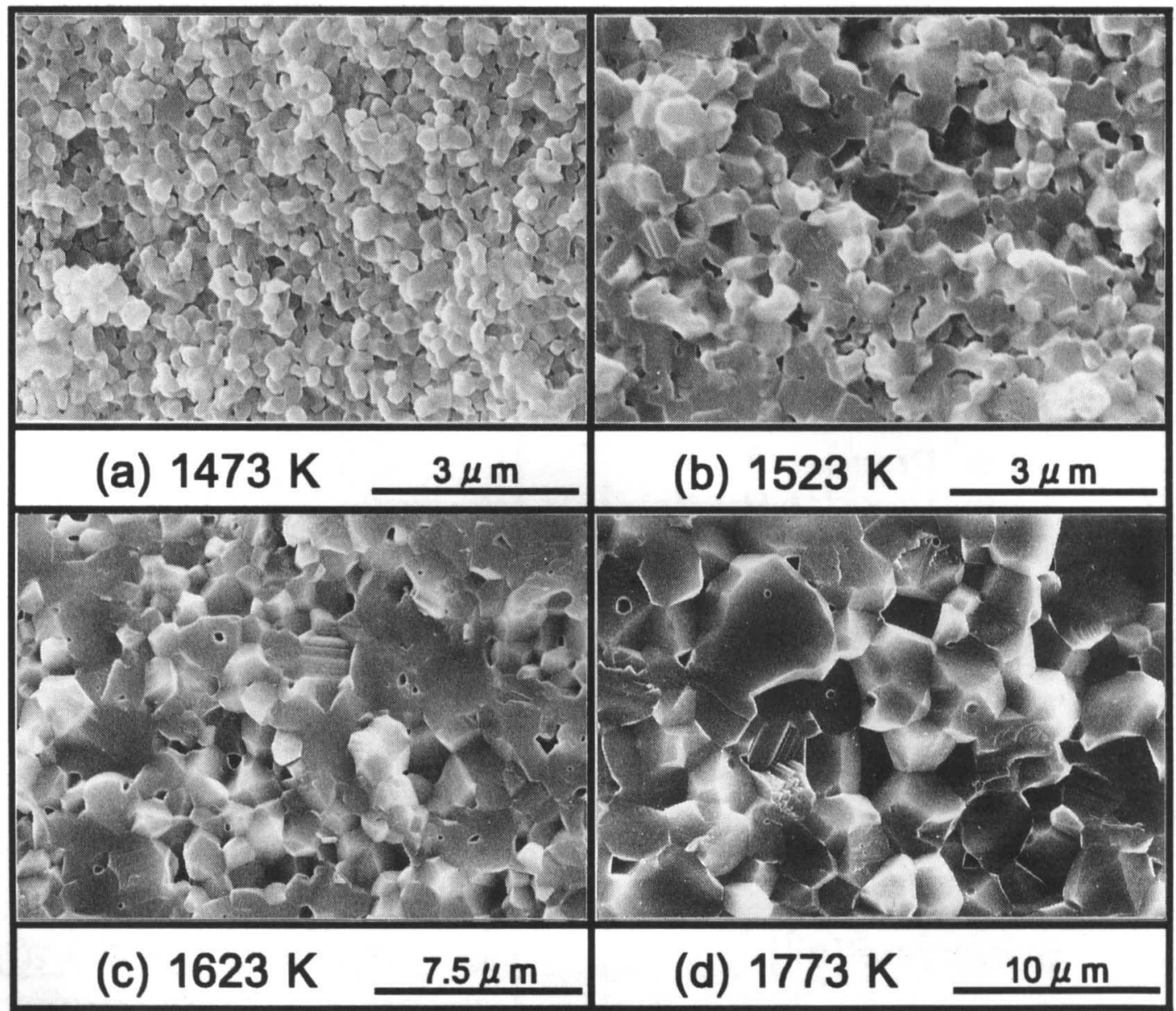

Fig.4 Fracture surfaces of compacts of powder A; sintered at $1423-1773 \mathrm{~K}$ for $5.4 \mathrm{ks}$. 
最終到達密度は約 99\%で，B粉焼結体が99.5\% 程度まで緻密 化するのに比べてやや低い。

次に両粉末の焼結体破面 (Fig.4) を比較すると, 温度 $1523 \mathrm{~K}$ のA粉焼結体の破面形態か' $1473 \mathrm{~K}$ の B 粉焟結体に近いなど, $\mathrm{A}$ 粉焼結体の方で焼結の遅れが認められる外，1623K以上で は， B 焼結体に見当たらなかった粒内気孔か幾つか認められ るようになる．粒内気孔はこれ以上の焼結温度になっても急 激に数が增えることはなく，またその寸法にも変化は見られ ない.A粉焼結体は $1823 \mathrm{~K}$ まで温度を上昇させて焼結を行っ ても異常粒成長等は現れず，均質性を保っており，全般的に は優れた焼結組織と言ってよい。

\subsection{3 結晶粒径}

次に,Fig5に両粉焼結体の焼結温度と結晶粒径の関係を示す。 両粉末とも焼結温度の上昇に伴って同じような形の粒成長 曲線を見せるが，両者を比較すると $\mathrm{A}$ 粉焼結体の方が $\mathrm{B}$ 粉焼 結体よりも粒成長が遅く，焼結温度が高くなるに従ってその 差が開いてゆく。

\section{4 粒径 / 密度曲線}

前節の結果より，各条件におけるA粉焼結体の相対密度を 横軸に, 結晶粒径を縦軸に取ってまとめたのがFig.6に示す粒 径 / 密度曲線である。点線の $\mathrm{B}$ 粉焼結体は既報》による。

$\mathrm{A}$ 粉焼結体の結果も $\mathrm{B}$ 粉焼結体と同様の曲線で表されるか， $\mathrm{A}$ 粉の曲線と $\mathrm{B}$ 粉の曲線は一部しか一致しておらず, 基本的 に両粉末は異なる粒径/密度曲線を持つことが分かる。少し詳 細に比較すると，相対密度約 $90 \%$ 以下の点(温度 1473K以下 の焼結体)で両曲線はほほ一致しているが，その隣の点 (1523K 焼結体)では $\mathrm{A}$ 粉の曲線は $\mathrm{B}$ 粉の曲線より上側に湾曲 を始めている.そして，A粉の曲線は密度 $98 \%$ 辺りで急激に 上側に向いて，その後はほほ直線的に上昇していく.

3.5 焼結条件と機械的特性の関係

次に，焼結温度によるA粉焼結体の硬さの変化を Fig.7に示

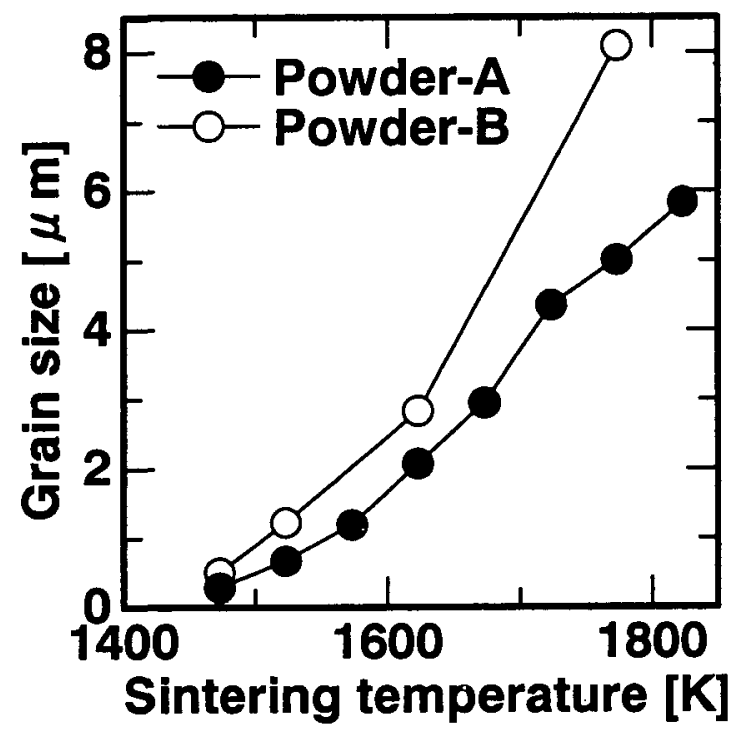

Fig.5 Grain sizes of compacts as a function of sintering temperature; sintered at $1473-1823 \mathrm{~K}$ for $5.4 \mathrm{ks}$.
す. 温度 1423KではHv約760であるが, 温度の上昇に伴って 硬さは急激に上昇し，1573Kで最高值 (Hv約 1950)を示す。こ の值は, B 粉焼結体の最大值 (Hv2130) よりも約 10\% 低い。 1573-1623Kの間で硬さは一旦低下するが, それ以上の温度で はほとんど変化が見られない。

次に，硬さが比較的優れている条件(1523-1673K)における 4 点曲げ強さの変化を Fig. 8 に示す. 温度 $1523 \mathrm{~K}$ および $1573 \mathrm{~K}$ の時は曲げ強さはいずれも高く, $1573 \mathrm{~K} て ゙$ 最高值(約 $850 \mathrm{MPa}$ ) を示す。焼結温度がこれ以上に上昇すると曲げ強さは隇少す る.

\section{6 焼結組織と硬さの関係}

前節の結果の中でテータ個数の多い硬さを選び, 相対密度 および粒径の関係に整理したのがFig.9, およびFig.10である.

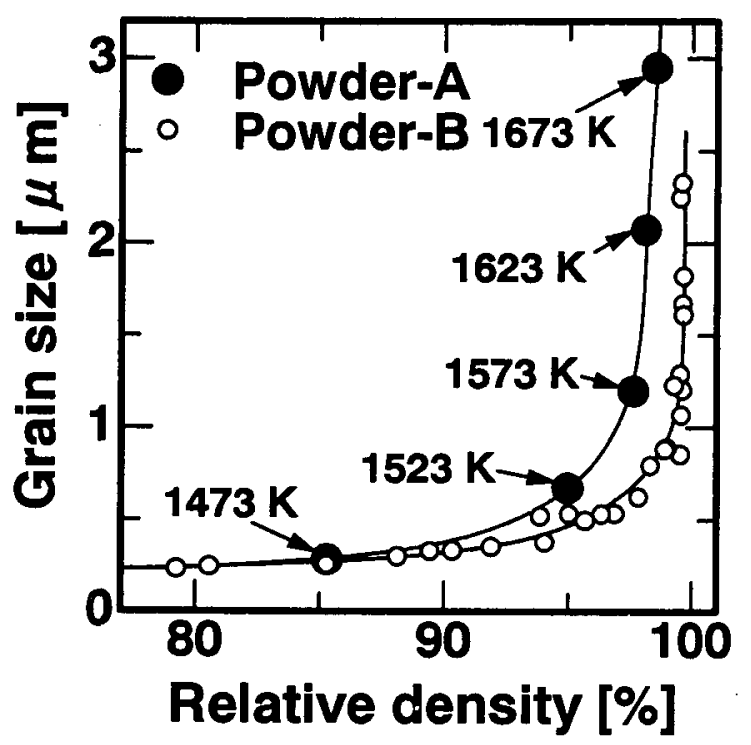

Fig.6 Grain-size/relative-density trajectories.

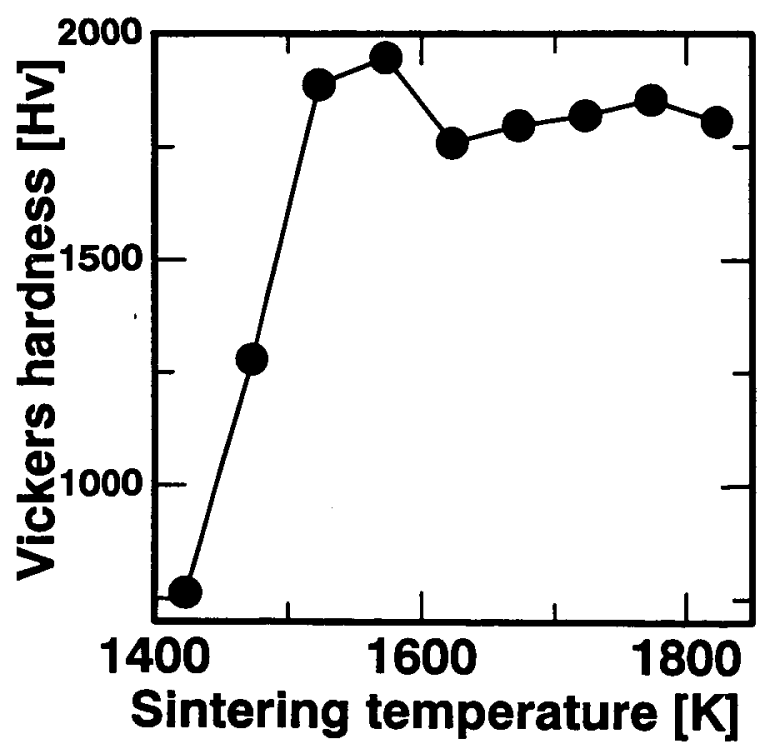

Fig.7 Vickers hardness of compacts of powder $A$ as a function of sintering temperature; sintered at $1423-1823 \mathrm{~K}$ for $5.4 \mathrm{ks}$. 
点線は，既報 ${ }^{4)}$ のB粉焼結体の結果を示している。まず，Fig.9 によると，密度約 $98 \%$ まではA, B両粉の焼結体の硬さはほほ 一致しており，それそれ相対密度の上昇に伴って硬さも上昇 する. その後, 密度と硬さの関係は A 粉焼結体では密度 $98 \%$ 以上で, また B粉焼結体では密度 $99 \%$ 以上でいずれも不明確 になる。

粒径との関係では, Fig.10に示すように A, B 両粉焼結体と もに粒径 $1.2 \mu \mathrm{m}$ (これは相対密度 $98 \%$ に対応)以下で粒径の僅 かな增大とともに硬さが急激に上昇し，一方粒径 $1.2 \mu \mathrm{m}$ 以上 になると，ばらつきがあるものの，粒径の増大に伴って硬さ は緩やかに低下していく．

以上の結果をまとめると, $\mathrm{A}$ 粉烤結体の硬さは, 相対密度

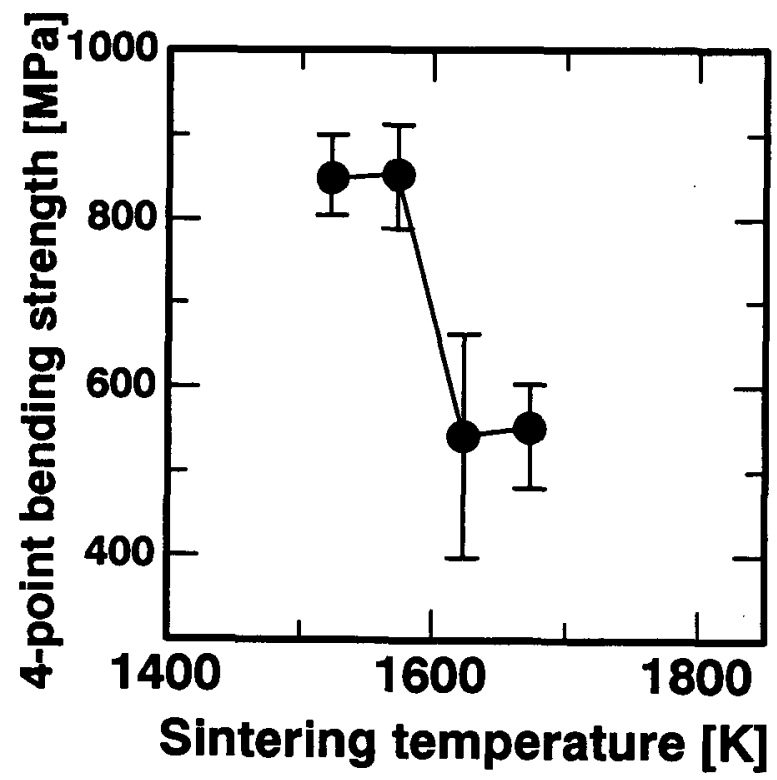

Fig.8 Four-point bending strength of compacts of powder $\mathbf{A}$ as a function of sintering temperature; sintered at 1523-1673 K for $5.4 \mathrm{ks}$.

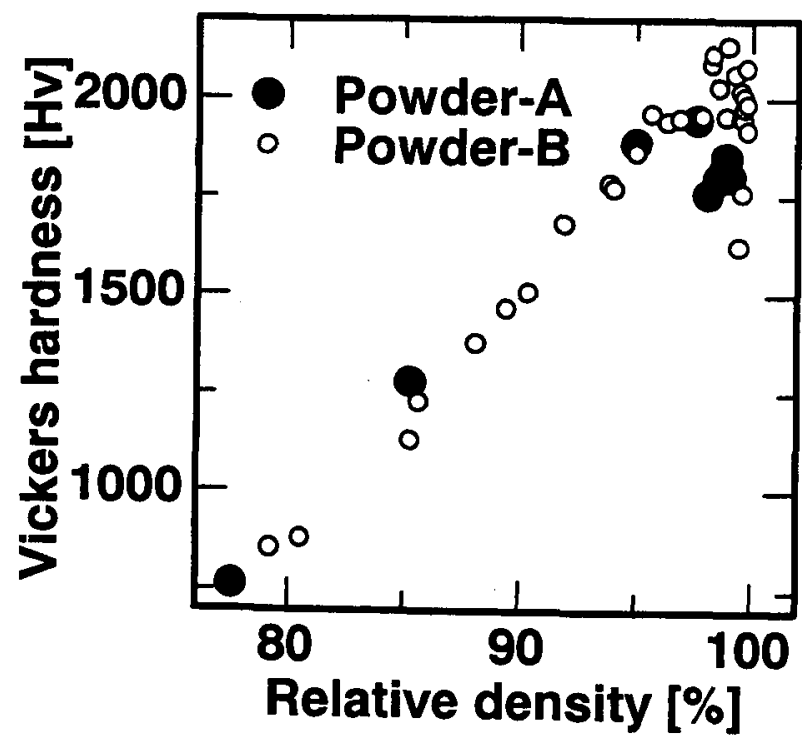

Fig.9 Relationship between relative density and Vickers hardness.
98\%で粒径 $1.2 \mu \mathrm{m}$ に達するまでは密度に従って上昇し，それ 以上では粒径の增大に伴って低下していくことがわかる.

\section{4 考莠}

4.1 成形性におよぼす粉末特性の影響

一般的に，成形性あるいは成形体の特性には，原料粉末の 特性以外に泥墏の調製条件が大きく影瞕する. 今回調製した 泥漿は両者とも，Fig.1に示すとおり全般的には低粘度であり 良好な分散状態が得られているにも関わらず，詳細に検討す ると, A 粉の泥墏の方が見かけ粘度のずり速度依存性が大き くてやや大きな準粘性挙動を示しており，粒子間の摩擦が大 きく調製状態としてはやや劣っている.これは, 今回の分散 剤添加量と泥墏調製条件が, B粉末に対する最適值であり, 比 表面積がB粉末に比べてやや小さいA粉末では分散郕が過剩 になっているためかも知れない8).

分散性の違いは成形体の組織にも影響していると考えられ る.Fig.2においてA粉成形体破面の方がB粉成形体に比べて 一つ一つの凹凸が大きいのは，粒子がより大きな単位で凝集 しているためであろうし，このために A 粉末の粒子充填率が B 粉末のそれよりやや低いものと考えられる。

4.2 焼結性におよぼす粉末特性の影響

\subsection{1 粒径/密度曲線を利用した焼結性の評価}

従来の研究では，一定の焼結条件のもとにおける維密化の 進行度合や，一定の焼結密度を得るための焼結条件によって 焼結性の評価をするものが多い.そして一般的には，より低 温短時間で緻密化か進行するものを焼結性が良いとしている. この方法で A, B両粉試料の焼結性を比較すると, Fig.3に示す ように A 粉試料の䋊密化の進行は $\mathrm{B}$ 粉試料より遅く，また $\mathrm{B}$ 粉試料が温度 $1503 \mathrm{~K} て ゙$ 相対密度 $99 \%$ の最適組織になるのに対 し，A 粉試料で同じ密度 $99 \%$ を得るためには約 $250 \mathrm{~K}$ 高い 1773Kまで焼結温度を上げる必要がある.すなわち，いずれ

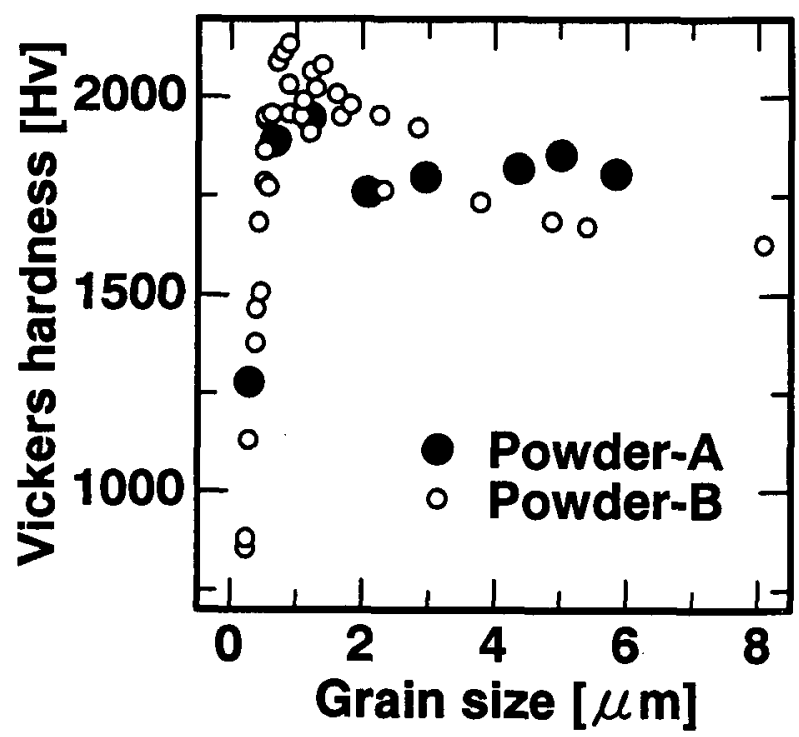

Fig.10 Relationship between grain size and Vickers hardness. 
の面から見てもA粉試料の方が焼結性は非常に劣ることにな る.さらに，このときの粒径はFig.5によると約 $5 \mu \mathrm{m}$ まで成長 しており，A粉は最終的に B 粉に比べて非常に好ましくない 組織をもたらすとの判断にもなりうる.

それに対し，既報と同じ形で粒径/密度曲線を利用して焼結 性の評価を行ってみる、Fig.6によると，密度が $80 \%$ から $90 \%$ 台前半辺りまでは A, B 両粉焼結体とも曲線は接近している. この密度範囲は既報 ${ }^{3}$ で述べた焼結の第 I 段階に当たり，開 放した気孔網を持つアルミナの骨格構造を有する。この段階 までは両粉末ともほほ同じ組織変化をたどっているが, 次に 密度 $95 \%$ になる A 粉焼結体の曲線が B 粉よりも上側に曲が り始める．この辺りは，密度の值から考えると組織中の気孔 網がほほ全て閉鎖気孔となる点に当たり，A 粉焼結体の曲線 は 98\%辺りまで湾曲しながら上昇していく．これは緻密化と 粒成長が刻々とその比率を変えながら進行する焼結の第 II 段 階に当たる．ここまでは，第 I，第II段階を合わせて緻密化 段階と言うこともできる。そして，密度 $98 \%$ (焼結温度 1573K) においてFig.4に示すように等方的な粒界気孔と一部の粒内気 孔を持つ等方的な組織が現れ，その後は粒成長がもつばら進 む焼結の第四段階(粒成長段階) となる．この密度 $98 \%$ (焼結 温度 1573K)の点では, 前述のように最も優れた機械的特性が 得られている。これを組織の面から見ると， $\mathrm{A}$ 粉焼結体も既 報で述へた B 粉焼結体の場合と同様に，緻密化段階と粒成長

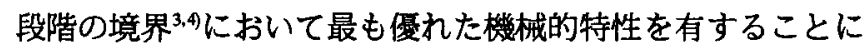
なる.

この様な評価方法によれば，A，B両粉試料の焼結中の組織 変化の違いは，一般に言われるよりも僅かであり，両者とも 基本的に優れた焼結性を示し，A粉末の焼結性も非常に優れ た部類に入る．すなわち，機械的特性を決定するのは，密度 (気孔率) と粒径の組み合わせ 2,3,9-11)であり，最高の特性が得 られる組み合わせは原料粉末によって異なる外，おそらく成 形方法によっても異なるであろう．従来のように，密度と粒 佳を焼結条件によって別々に評価する方法では，それらの最 適の組み合わせも，その組み合わせを得る焼結条件も，見出 すことは困難であり,粒径/密度曲線を描くことこそ，それら を見出す上で効果的である。

また，粒径/密度曲線では，焼結性の違いをすかりやすく表 示することができるため, 焼結性の違いの具体的な検討が可 能である。例えば，密度 $95 \%$ 付近からA粉焼結体の曲線が上 側に移動しているから，A粉焼結体は気孔か閉鎖してからの 焼結性が劣ることが分かる。

\section{2 .2 焼結性少化の原因}

平均粒径が同一の粉末を使用したときに焼結性に違いが生 しる原因としては,粉末の比表面積や純度の違いが考えられる。

まず，粉末は比表面積の大きいものの方が一般的に焼結性 が良いとされ，確かにFig.3でも1423Kの低温焼結時には比表 面積の大きいB粉末の方が $\mathrm{A}$ 粉末に比べて緻密化が速く進行 している.しかし，両粉末の焼結における粒径/密度曲線を比 較すると，焼結初期の段階 Iでは曲線に違いがない．単に，
初期焼結時の綊密化の進行度合いが異なるために，その後の A 粉焼結体の緻密化と粒成長の進行度合いが B 粉末に対して 遅れているのかも知れない，そのように考えると，セラミッ クスのように完全に䋊密化させる必要のある焼結材の原料の 良否は，必ずしも緻密化の早さおよびそれをもたらす比表面 積によって決めるべきものではないであろう.

次に，粒子表面の残留不純物の影響について考える。通常 アルミナの焼結では, 異常粒成長を抑制するためにMgOを添 加する必要がある ${ }^{12,13)}$ とされているが，今回の実験では A, B 両粉末とも焼結助剂の添加なしで健全に緻密化している.こ れは，両粉末とも基本的に高純度であり，異常粒成長を引き 起こしやすい NaやCa といった不純物 ${ }^{1410}$ をほとんど含んで いないためであると考えられる．また加えて，成形中にも不 純物の混入が少ないこと1),さらに焼結温度が低く時間も短か いため，炉壁からの不純物の混入神も少ないことか，安定し た焼結挙動に寄与しているものと思われる。

不純物の影響は，異常粒成長の発生による焼結組織の劣化 に加えて, 全般的な緱密化や粒成長速度の変化, すなわち粒 径/密度曲線の変化にも影響を与えうる.本研究のものとほぼ 同じ純度と特性を持ったアルミナ粉末を使用し，乾式プレス 法で成形した他の報告 ${ }^{18,19)}$ では，焼結温度も $1800 \mathrm{~K}$ 以上を必 要としており,その粒径/密度曲線は本研究の結果に比へて極 端に左上側, すなわち低密度, 粗大粒径側に移動している.こ れには不純物の構成以外の要素が, 焼結性に大きな影響を与 えていることが予想される。

A, B両焼結体は, 焼結組織に最も顕著な違いが認められる. すなわち，A粉焼結体の組織には，Fig.4に示すように，B粉 焼結体には認められない粒内気孔が存在している.Zhaoらは， 成形体の不均質性が粒径/密度曲線に与える影響を実験的およ び解析的に検討し2021), 焼結組織内に様々な大きさの気孔が存 在する場合には，均一径の気孔が存在する場合に比べて，粒 径/密度曲線がより左上側に移動して焼結組織が劣るようにな るという.また, 焼結の進行と気孔の位置の変化を観察した 既報 ${ }^{2)}$ において，粒成長によって小さな粒が消滅するのに 伴って気孔が粒内に取り込まれることを考察したが,成形組 織の不均一性が大きい場合は，小粒子が多く消滅する部分に 早い段階から粒内気孔が発生する可能性も考えられる.さら に, 気孔の初期半径と最終的な平衡半径の関係を解析した Kang 社)の告にあるように，気孔の初期半径が大きい場合 は気孔の最終半径も大きくなるから, 粒内気孔の発生は別に しても最終維密化が阻害される可能性も考えられる.一方, 4.1節で検討しているように，A粉成形体の性質は B 粉成形体 に比ベてやや劣っており，A成形体の方が大きな空隙を含ん でいる可能性が高い。この成形組織のわずかな違いか，両焼 結体の粒径/密度曲線が僅かに異なる原因になっている可能性 がある。

\section{3 機械的特性におよぼす粉末特性の影翌}

4.3.1 機械的特性におよほす組織の影響

セラミックスの強度は, いわゆる最弱リンク説で示される 
ように，組織の平均的な大きさよりも，少数ながら大きな欠 陥があればそれによって決まる.従って，同じ密度(すなわち 気孔率)や粒径を持っていても，その寸法分布に違いがあった り，偶発的な欠陥が含まれていたりすれば，強度には違いか 生じるはずである。しかし，Fig.9, Fig.10によると，硬さの密 度や粒径への依存性はいずれも両粉の焼結体でよく一致して おり，その点では既報りに提唱した回帰式を使用して硬さの 組織依存性を評価できることが分かる。これは回帰式の有効 性を検証する結果であるとともに，間接的に，HCP 法による アルミナが原料粉末に関わらず久陥の少ない均質な焼結組織 を持つことを示している.4点曲げ強さに関しても，今回は測 定点が少ないために具体的には検討していないが，既報で提 唱した組織と曲げ強さの回㷌式が適用できると考えられる. 4.3.2 焼結組織と機械的特性の統合的評価

A, B両粉焼結体の機械的特性が同じ回㴆式によって表現で きるのであれば，既報》にに示した材質一組織ダイヤグラムが そのままA粉にも利用できることになる.A，B両粉の粒径/密 度曲線を記入した硬さ一組織ダイヤグラムを Fig.11に，曲げ 強さ一組織ダイヤグラムを Fig.12に示す.

A 粉焼結体において硬さ，曲げ強さが最も優れた密度 $98 \%$ の点が，等硬度，等強度曲線の最も高いものに接しうること が分かる.またこの図より，B粉焼結体に比べて A 粉焼結体 の機械的特性が,粒径/密度曲線が左上側に移動している分だ け劣ることも容易に分かる.

以上のように，材質一組織ダイヤグラムを使用すると，出 発原料の異なるHCPアルミナについて，それそれ最良の機械 的特性を与える組織を予測することができる。またこれらの 図から,粒径/密度曲線がより右下側に来るような原料を使用 することで,より機械的特性に優れたアルミナが得られるこ とも予想できる.さらにこの考え方を発展させれば，他のセ ラミックスや粉末冶金製品にも応用できる可能性がある。

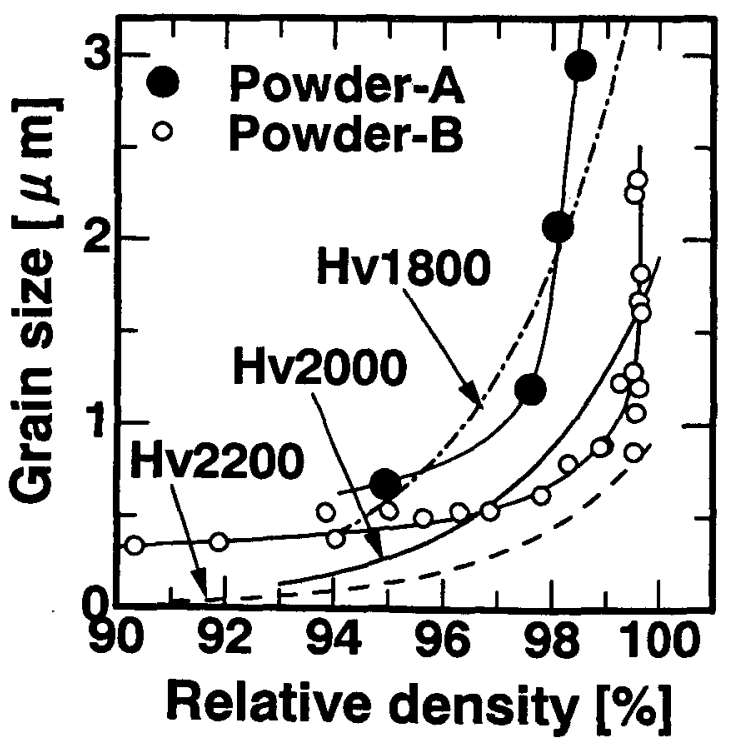

Fig.11 Vickers-hardness-microstructure diagram.

\section{5 結言}

製法が異なる2種類の高純度アルミナ粉末を使用して高速 遠心成形を行い，両粉末の成形性，焼結性および機械的特性 を比較検討して，以下の結果を得た。

原料粉末が変わっても，一般的に高速遠心成形法による成 形体は充填密度が高く均質であり，1573K の低温で異常粒成 長等の見られない均質で高強度の焼結体になるなど焼結性に も優れているが，それらの特性は泥墏の分散性の良い粉末の 方が優れている.

焼結体の機械的特性の組織依存性は原料粉末が変わっても 同一傾向であり,粉末毎に粒径/密度の関係は別の曲線を描く が，緻密で微細な組織であるほど高強度を与える．最高強度 の組織は，いずれの曲線でも絰密化段階と粒成長段階の境界 に当たる点で示される。

硬さ一組織ダイヤグラムおよび曲げ強さ一組織ダイヤグラ ムにおいて, 粒径/密度曲線がなるべく右下にくる原料粉末を 使用することにより，高強度の焼結体を得ることができる.

\section{謝辞}

本研究の一部は, 文部省科学研究費補助金，並びに(財)広 島県産業技術振興機構の助成を受けて行われたことを付記し， 謝意を表します。

\section{文 献}

1) S.Tashima, S.Hashimoto and H.Kuroki: "High Speed Centrifugal Compaction and Low temperature Sintering of Submicron Alumina Powder", J. Japan Soc. Powder and Powder Metal., 41(1994)180-183.

2) H.Y.Suzuki, K.Shinozaki and H.Kuroki: "Morphological Development of Pores during Sintering in High Purity Alumina Formed by High-Speed Centrifugal Compaction Process", J.

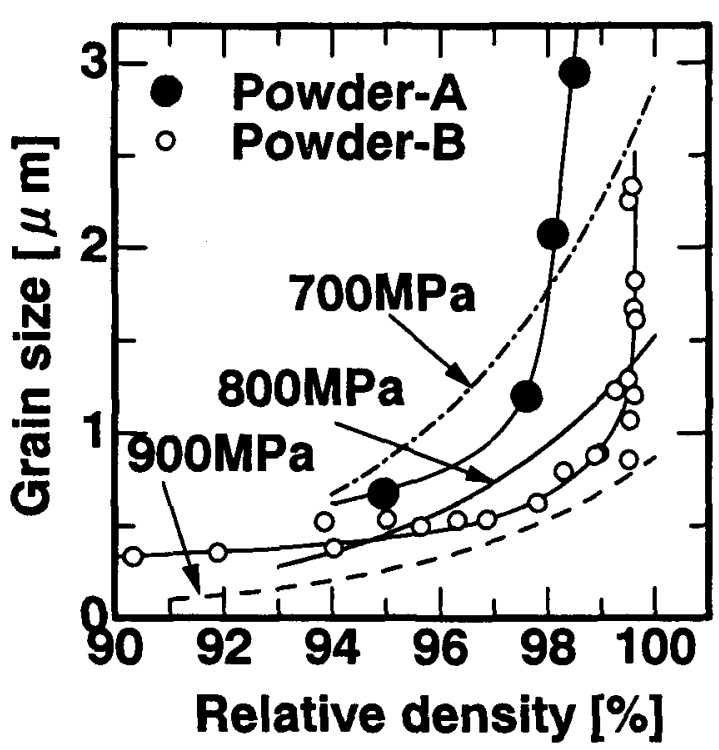

Fig.12 Bending-strength-microstructure diagram. 
Japan Soc. Powder and Powder Metal., 45(1998)473-479.

3) H.Y.Suzuki, K.Shinozaki, M.Murai and H.Kuroki: "Quantitative Analysis of Microstructure Development during Sintering of High Purity Alumina Made by High-Speed Centrifugal Compaction Process", J. Japan Soc. Powder and Powder Metal., 45(1998)1122-1129.

4) H.Y.Suzuki, K.Shinozaki, S.Tashima and H.Kuroki: "Dependence of Mechanical Properties on Sintered Microstructure of High Purity Alumina Made by High-Speed Centrifugal Compaction Process", J. Japan Soc. Powder and Powder Metal., 46(1999)331-338.

5) M.I.Mendelson: "Average Grain Size in Polycrystalline Ceramics", J. Am. Ceram. Soc., 52(1969)443-446.

6) 小野木重治著 : " 化学者のためのレオロジー", 化学同人, (1982)14.

7) 水田博之, 小田喜一, 芝崎靖雄: " 真空 - 加圧鋳込成形法 を用いた高密度・高強度アルミナ焼結体の作製 ", ニュー セラミックス,7(1990)87-94.

8) T.Kimura, S.Sakaguchi and M.Nakamura: "The Correlation Between the Casting Behaviour and the Particle Aggregated Structure of Fine Ceramics in a Concentrated Slurry", J. Soc. Powder Technol. Japan, 33(1990)371-378.

9) F.P.Knudsen: "Dependence of Mechanical Strength of Brittle Polycrystalline Specimens on Porosity and Grain Size", J. Am. Ceram. Soc., 42(1959)376-387.

10) E.M.Passmore, R.M.Spriggs and T.Vasilos: "Strength-Grain Size-Porosity Relation in Alumina", J. Am. Ceram. Soc., 48 (1965)1-7.

11) S.C.Carniglia: "Reexamination of Experimental Strength-vsGrain-Size Data for Ceramics", J. Am. Ceram. Soc., 55(1972)
243-249.

12) R.L.Coble: "Sintering Crystalline Solids. II. Experimental Test of Diffusion Models in Powder Compacts", J. Appl. Phys., 32 (1961)739-799.

13) R.L.Coble: "Transparent Alumina and Method of Preparation", U. S. P. 3026210, (1962).

14) H.Song and R.L.Coble: "Origin and Growth Kinetics of Platelike Abnormal Grains in Liquid-Phase-Sintered Alumina", J. Am. Ceram. Soc., 73(1990)2077-2085.

15) S.I.Bae and S.Baik: "Deterioration of Critical Concentrations of Silica and/or Calcia for Abnormal Grain Growth in Alumina", J. Am. Ceram. Soc., 76(1993)1065-1067.

16) S.I.Bae and S.Baik: "Critical Concentration of $\mathrm{MgO}$ for the Prevention of Abnormal Grain Growth in Alumina", J. Am. Ceram. Soc., 77(1994)2499-2504.

17) S.I.Bae and S.Baik: "Sintering and Grain Growth of Ultrapure Alumina", J. Mater. Sci., 28(1993)4197-4204.

18) K.A.Berry and M.P.Harmer: "Effect of $\mathrm{MgO}$ on Microstructure Development in $\mathrm{Al}_{2} \mathrm{O}_{3}$ ", J. Am. Ceram. Soc., 69(1986)143-149.

19) J.Zhao and M.P.Harmer: "Sintering of Ultra-High-Purity Alumina Doped Simultaneously with $\mathrm{MgO}$ and FeO", J. Am. Ceram. Soc., 70(1987)860-866.

20) J.Zhao and M.P.Harmer: "Effect of Pore Distribution on Microstructure Development: I, Matrix Pores", J. Am. Ceram. Soc., 71(1988)113-120.

21) J.Zhao and M.P.Harmer: "Effect of Pore Distribution on Microstructure Development: II, First- and Second-Generated Pores", J. Am. Ceram. Soc., 71(1988)530-539.

22) S.L.Kang and K.J.Yoon: "Densification of Ceramics Containing Entrapped Gases", J. Euro. Ceram. Soc., 5(1989)135-139. 